\section{Silvia Badim Marques}

Sueli Gandolfi Dallari

\title{
G arantia do direito social à assistência farmacêutica no Estado de São Paulo
}

\author{
Safeguarding of the social right to \\ pharmaceutical assistance in the \\ state of São Paulo, Brazil
}

RESU MO

OBJETIVO: Analisar como o Poder Judiciário vem garantindo o direito social à assistência farmacêutica e qual a relação do sistema jurídico e político na garantia a esse direito.

MÉTODOS: Foram analisados os processos judiciais de fornecimento de medicamentos pelo Estado de São Paulo, de 1997 a 2004. Utilizou-se o Discurso do Sujeito Coletivo para identificar os discursos dos atores que compõem os processos judiciais.

RESULTADOS: Os discursos dos juízes subsidiaram a condenação do Estado em 96,4\% dos casos analisados. O Estado foi condenado a fornecer o medicamento nos exatos moldes do pedido do autor, inclusive quando o medicamento não possuía registro na Agência Nacional de Vigilância Sanitária (9,6\% dos casos analisados). Observou-se que $100 \%$ dos processos estudados foram propostos por autores individuais; em 77,4\% o autor requer o fornecimento de medicamento específico de determinado laboratório farmacêutico e; em 93,5\% dos casos, o medicamentos são concedidos judicialmente ao autor em caráter de urgência, por meio de medida liminar.

CONCLUSÕES: O Poder Judiciário, ao proferir suas decisões, não toma conhecimento dos elementos constantes na política pública de medicamentos, editada conforme o direito para dar concretude ao direito social à assistência farmacêutica. $\mathrm{E}$ assim, vem prejudicando a tomada de decisões coletivas pelo sistema político nesse âmbito, sobrepondo as necessidades individuais dos autores dos processos às necessidades coletivas.

DESCRITO RES: Serviços de assistência farmacêutica, legislação e jurisprudência. Legislação sanitária. Poder Judiciário. Controle de medicamentos e entorpecentes. Eqüidade no acesso. Pesquisa qualitativa.

\section{ABSTRACT}

Pública. Faculdade de Saúde Pública.

Universidade de São Paulo. São Paulo, SP,

Brasil

\section{Correspondência | Correspondence: Silvia Badim Marques \\ Av. Dr. Arnaldo, 715 Sala 102 \\ 01246-904 São Paulo, SP, Brasil \\ E-mail: sbadim@usp.br}

Recebido: 15/2/2006 Revisado: 16/10/2006 Aprovado: 7/11/2006
OBJECTIVE: To evaluate how the Judicial Power safeguards the social right to pharmaceutical assistance as well as the relationships between the legal and political systems to safeguard this right.

METHODS: There were assessed decisions in lawsuits of drug supply in the state of São Paulo, Southern Brazil, between 1997 and 2004. Discourse of the Collective Subject of procedural actors was the methodological approach used.

RESULTS: In $96.4 \%$ of the cases analyzed, judges' discourse sentenced the State. In 
these cases, the State was obliged to provide drugs exactly as requested by the plaintiff, even when drugs were not registered in the National Health Surveillance Agency (9.6\% of cases). Also, $100 \%$ of the lawsuits were proposed by individual plaintiffs; in $77.4 \%$ of the cases the plaintiff requested an specific drug of a specific pharmaceutical company; and in $93,5 \%$, the drugs were provided to the plaintiff through an urgent preliminary order.

CONCLUSIONS: The Judicial Power is not taking into account in its decisions political elements of drug policies, established to enforce the social right to pharmaceutical assistance. The Judicial Power is hindering the collective decision making process by the political system, prioritizing plaintiffs' individual needs over community interests.

\section{KEYW O RD S: Pharmaceutical services, legislation \& jurisprudence. Laws, Health. Judicial Power. Drug and narcotic control. Equity in access. $Q$ ualitative research.}

\section{INTRO DUCCÃO}

A Constituição Federal de 1988 direciona a atuação do Estado brasileiro para a consecução do bem-estar social e da plena cidadania, instituindo no ordenamento jurídico determinados direitos sociais, como o direito à saúde e à educação, direcionando a atuação do Estado para garantí-los.

Segundo Silva, ${ }^{12}$ os direitos sociais "são prestações positivas proporcionadas pelo Estado direta ou indiretamente, enunciadas em normas constitucionais, que possibilitam melhores condições de vida aos mais fracos, direitos que tendem a realizar a igualização de situações sociais desiguais. São, portanto, direitos que se ligam ao direito de igualdade" (p. 289-290). A concretização dos direitos sociais dependem da elaboração e implementação de políticas públicas e serviços públicos pelo Estado, ou seja, da criação de condições materiais para seu exercício. São direitos que se ligam ao ideal de justiça distributiva e, assim, vinculam ativamente o sistema político e o sistema jurídico, para a sua garantia, conforme Kuntz. ${ }^{6}$ Portanto, demandam uma outra relação entre o sistema jurídico e o sistema político para a sua garantia, diferente da relação até então estabelecida para a proteção dos direitos individuais. Como salienta Lopes, ${ }^{8}$ os direitos sociais "têm uma implicação política inovadora na medida em que permitem a discussão da justiça geral e distributiva" (p. 127).
O direito à saúde é positivado no ordenamento jurídico como um direito social, de acordo com o Artigo $6^{\circ}$ da Constituição Federal. Os artigos 196 a 201 da Constituição Federal instituem uma estrutura política complexa e abrangente para o sistema de saúde brasileiro, com a organização do Sistema Único de Saúde (SUS) que integra a União, os Estados, os Municípios e o Distrito Federal. O artigo 196 estabelece expressamente que a saúde é "direito de todos e dever do Estado, garantido mediante políticas sociais e econômicas que visem à redução do risco de doença e de outros agravos e ao acesso universal e igualitário às ações e serviços para a sua promoção, proteção e recuperação". O direito à assistência farmacêutica, como parte integrante do direito social à saúde, também é instituído no ordenamento jurídico como um direito social. De acordo com os artigos $6^{\circ}$ e $7^{\circ}$ da Lei Orgânica da Saúde, ${ }^{*}$ as assistências terapêuticas e farmacêuticas devem ser garantidas integralmente aos cidadãos brasileiros, de acordo com o princípio da integralidade de assistência.

Para que o Estado brasileiro possa atender esses preceitos legais, é preciso que sejam implementadas políticas públicas e serviços públicos de saúde e assistência farmacêutica, em escala coletiva. Dessa forma, o sistema jurídico e o político participam ativamente na garantia do direito social à assistência farmacêutica. Constata-se, em consequiência, a existência de série de atos administrativos emanados tanto do Ministério da 
Saúde do Brasil,* quanto da Secretaria de Estado da Saúde de São Paulo,** instituindo uma política pública de medicamentos em nível federal e estadual, com base nas diretrizes contidas na Constituição Federal e na Lei Orgânica de Saúde. A política pública implementada em matéria de medicamentos e assistência farmacêutica visa a racionalizar a prestação coletiva e envolve. Dentre outros preceitos, essa política estabelece critérios justificados de inclusão e exclusão de medicamentos dentre os medicamentos ofertados pelo SUS à população. Tais critérios são formalizados juridicamente por meio dos atos administrativos que compõem os Protocolos Clínicos e Diretrizes Terapêuticas, emanados do Ministério da Saúde. A política assim implementada e os serviços públicos prestados possuem limitações quanto às necessidades terapêuticas de toda a população brasileira. A política é elaborada com base na tomada de decisões coletivas pelo sistema político, sob uma perspectiva coletiva e distributiva.

O objetivo do presente trabalho foi analisar como o sistema jurídico vem garantindo o direito social à assistência farmacêutica por meio da prestação jurisdicional.

\section{ANÁLISE DOS PRO CESSO S JUDICIAIS}

Foram pesquisados os processos judiciais que tinham por objeto o fornecimento de medicamentos e insumos pelo Estado, nas Varas da Fazenda Pública do Estado de São Paulo. Foram analisados os seis últimos livros de sentença editados e disponíveis nos Cartórios das Varas da Fazenda Pública. A pesquisa foi realizada no período de agosto a dezembro de 2004 e os períodos dos livros de sentença variaram entre os meses de março a novembro de 2004, abarcando $71,4 \%$ das Varas existentes.

Fez-se a opção pela análise dos seis últimos livros de sentença disponíveis pela maior probabilidade de se localizar, em Cartório, os respectivos processos. Buscou-se identificar sentenças proferidas em processos que tinham por objeto o fornecimento de medicamentos e insumos pelo Estado, este representado por qualquer ente federativo ou entidade autárquica. Em seguida, foram também identificados os respectivos processos, catalogados por número e Vara. Os processos localizados variaram entre os anos de 1997 e 2004. Foram requisitadas ao Tribunal de Justiça do Estado de São Paulo xerocópias das seguintes peças processuais: petição inicial, contestação ou defesa do Estado e sentença do juiz de primeiro grau, obtendo-se xerocópias de 31 processos.

Foram transcritos os principais argumentos trazidos aos autos pelos três atores: autor, réu e juiz, cada qual com interesses e discursos específicos, que dialogam entre si dentro do campo processual. Os textos constantes das peças processuais foram tomados como unidade de análise, dos quais foram extraídos os argumentos preponderantes (Minayo, ${ }^{9}$ p. 214).

Seguindo Lefèvre \& Lefèvre, ${ }^{7}$ buscou-se as descrições dos argumentos nos diferentes grupos em escala coletiva para confrontá-las. Ou seja, a partir dos textos das peças processuais, os discursos encontrados em cada grupo (dos autores, dos réus e dos juízes) foram somados utilizando a metodologia do discurso do sujeito coletivo, ${ }^{7}$ que se destina a fazer a coletividade falar diretamente. $\mathrm{O}$ discurso do sujeito coletivo ${ }^{7}$ sintetiza, na primeira ou terceira pessoa do singular, o pensamento ou interesse social de uma dada coletividade sobre determinado tema. Cada processo recebeu uma ficha com um número específico (de 1 a 31 ), contendo as principais argumentações de seus atores. A partir desses argumentos, foram identificadas as expressõeschave, expressões-chave homogêneas (que foram agrupadas) e as respectivas idéias centrais. Posteriormente, foi construído o discurso do sujeito coletivo ${ }^{7}$ de cada grupo de atores processuais.

\section{RESU LTAD OS DA ANÁLISE}

A seguir, encontram-se as idéias centrais que compõem o discurso do sujeito coletivo elaborado, em relação a cada grupo de atores.***

\section{Discursos do sujeito coletivo}

\section{Autores processuais}

Todos os autores processuais se enquadravam na ca-

\footnotetext{
*Ministério da Saúde. Portaria n. 3.916, de 10 de novembro de 1998. Aprova a Política Nacional de Medicamentos. Diário O ficial da U nião, 10 nov 1998;Seção 1. Ministério da Saúde. Portaria n. 507/GM, de 27 de abril de 1999. Publica a revisão da Relação Nacional de Medicamentos Essenciais - RENAME. Diário O ficial da União, 27 abr 1999;Seção 1. Ministério da Saúde. Portaria n. 131/GM, de 1 de fevereiro de 2001. Diário Oficial da União, 1 fev 2001;Seção 1. Ministério da Saúde. Portaria n. 373/GS, de 27 de fevereiro de 2002 . Aprova, na forma do anexo desta portaria, a norma operacional da assistência à saúde - NOAS-SUS 01/2002 que amplia as responsabilidades dos municípios na atenção básica; estabelece o processo de regionalização como estratégia de hierarquização dos serviços de saúde e de busca de maior equidade; cria mecanismos para o fortalecimento da capacidade de gestão do sistema único de saúde e procede a atualização dos critérios de habilitação de estados e municípios. Diário Oficial da União, 28 fev 2002;Seção 1.

**Secretaria de Estado da Saúde de São Paulo. Plano estadual de assistência farmacêutica básica 'Dose Certa': ano 2002. Disponível em http://www.farma.saude.sp.gov.br/Anexos/DO SE CERTA-2.0022.doc [acesso em 28 set 2004]

***O s discursos do sujeito coletivo, na íntegra, podem ser encontrados em Marques SB. A relação do sistema jurídico e do sistema político na garantia do direito social à assistência farmacêutica: o caso do Estado de São Paulo [dissertação de mestrado]. São Paulo: Faculdade de Saúde Pública da Universidade de São Paulo; 2005.
} 


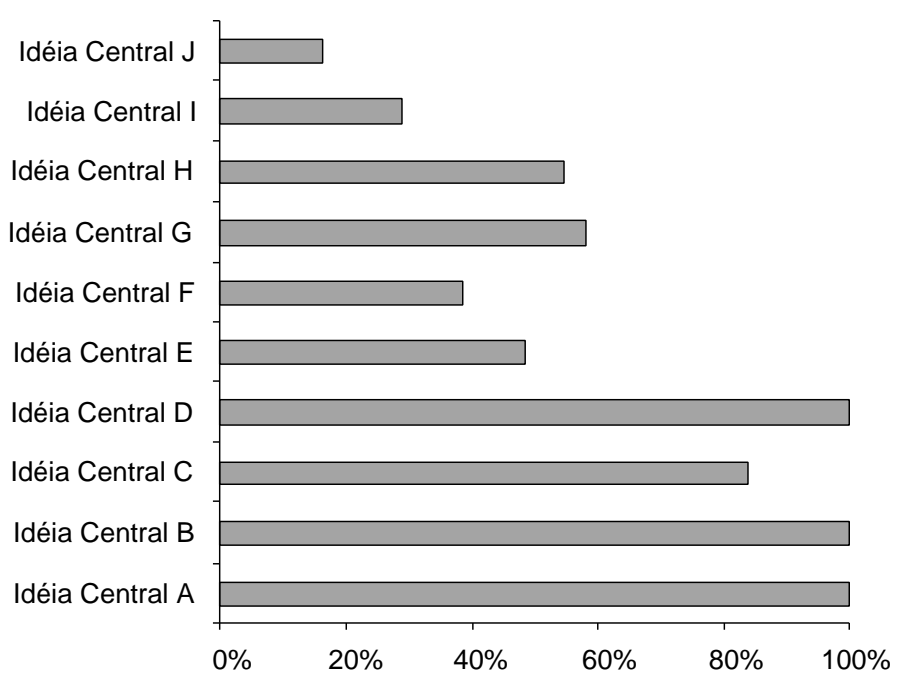

Figura 1 - Freqüência da incidência das idéias centrais dos autores. Estado de São Paulo, 1997 a 2004. voravelmente em pedidos semelhantes ao do autor;

- idéia central I. A política de assistência farmacêutica do Estado possui falhas e, por isso, não contempla o medicamento pleiteado;

- idéia central J. O Estado deve reparar o dano material e moral causado ao autor em decorrência de sua omissão.

A incidência de cada idéia central, sobre o total de discursos, encontra-se na Figura 1.

\section{Réus}

Em $61 \%$ dos casos figurava como réu nos processos o Secretário de Estado da Saúde de São Paulo e, em 22\%, a Fazenda Pública do Estado de São Paulo. tegoria de autor individual, $67,7 \%$ representados por advogados particulares e destes, $23,8 \%$ possuíam o apoio de associações. Em 35,5\% dos processos apareceu expressamente o nome do laboratório farmacêutico no pedido do autor e, em 77,4\% dos casos, o autor requereu pelo menos um medicamento ou insumo (dos demais pleiteados) de uma determinada marca, sobrepondo o nome fantasia do medicamento ou insumo ao seu nome genérico.

As idéias centrais encontradas nos discursos do grupo de autores foram as seguintes:

- idéia central $A$. O autor é portador de uma determinada doença, que está colocando em risco a sua vida ou a sua saúde;

- idéia central B. O medicamento prescrito pelo profissional médico que assiste o autor representa um avanço científico e é o único capaz de controlar a moléstia que lhe acomete;

- idéia central C. O autor não possui condições financeiras para adquirir o medicamento;

- idéia central D. O direito do autor à saúde e à assistência farmacêutica integral é um direito fundamental, garantido por Lei;

- idéia central E. As leis que subsidiam o direito à saúde e à assistência farmacêutica compreendem o fornecimento do medicamento específico necessitado pelo autor;

- idéia central $F$. Os direitos à saúde e à assistência farmacêutica não dependem de regulamentação infraconstitucional para serem exercidos;

- idéia central G. Os direitos fundamentais à saúde e à assistência farmacêutica não podem ser condicionados por políticas públicas de saúde ou por questões orçamentárias;

- idéia central H. Os juízes têm se manifestado fa-
As idéias centrais identificadas nos discursos dos réus foram:

- idéia central A. Nenhum ato ou omissão de autoridade de saúde violou direito líquido e certo do autor;

- idéia central B. O pedido do autor não se enquadra na padronização da Política de Assistência Farmacêutica para o tratamento da respectiva doença, não merecendo prosperar;

- idéia central $C$. O medicamento pleiteado não possui registro da Agência Nacional de Vigilância Sanitária (Anvisa), não podendo ser comercializado no Brasil;

- idéia central D. O Estado possui limitações legais e orçamentárias que obstam a garantia da pretensão do autor;

- idéia central E. O Poder Judiciário não pode ser transformado em um co-gestor dos recursos destinados à saúde pública. Isso implica em afronta ao princípio da separação dos poderes do Estado;

- idéia central F. O Estado de São Paulo não é a pessoa jurídica de direito público competente para figurar no pólo passivo da ação;

- idéia central $G$. O direito à saúde deve ser interpretado em consonância com os demais preceitos constitucionais, de forma a atender os interesses de toda a coletividade. Atender à pretensão do autor é sobrepor o individual ao coletivo;

- idéia central H. Não há possibilidade de se garantir pretensão futura e incerta, como no caso de medicamentos ainda não prescritos ao autor. $\mathrm{O}$ pedido deve ser certo e determinado;

- idéia central I. O Estado não pode ser responsabilizado por eventuais danos morais e materiais que o autor alega ter sofrido, em decorrência da falta da medicação. 


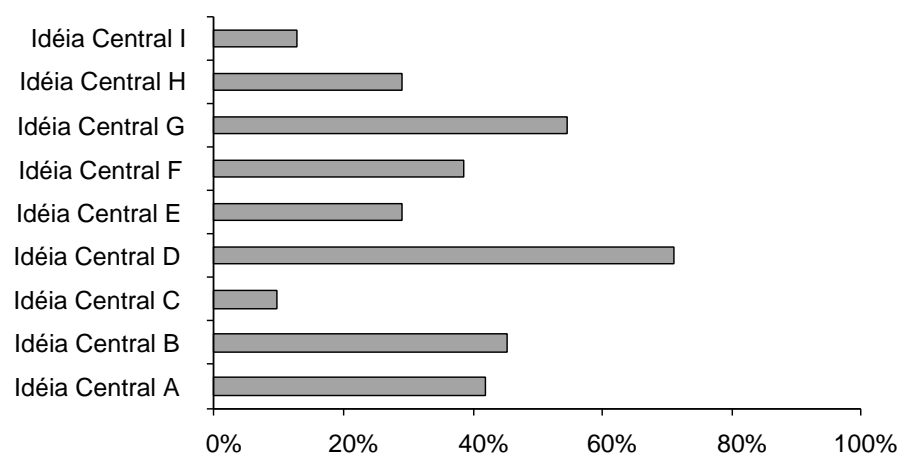

Figura 2 - Freqüência da incidência das idéias centrais dos réus. Estado de São Paulo, 1997-2004.

A incidência de cada idéia central dos discursos dos réus encontra-se na Figura 2.

\section{Juízes}

Dentre as decisões judiciais analisadas, 93,5\% das decisões interlocutórias concederam liminar para que o Estado seja compelido a fornecer o medicamento pleiteado pelo autor. Das sentenças proferidas pelos juízes, 90,3\% julgaram a ação procedente, condenando o Estado de São Paulo a fornecer a medicação pleiteada pelo autor. Porém, nenhuma sentença julgou o pedido do autor improcedente com o exame do mérito da ação, sendo que $96,4 \%$ das sentenças que julgavam o pedido procedente condenaram o requerido a fornecer o medicamento exatamente nos moldes requeridos pelo autor na petição inicial. Em 10,7\% das sentenças o Estado foi condenado a fornecer também outros medicamentos que venham a ser prescritos ao autor, de acordo com prescrição médica futura.

As idéias centrais identificadas nos discursos dos juízes foram:

- idéia central A. O Estado de São Paulo, bem como seu Secretário de Estado da Saúde, são competentes para compor o pólo passivo da ação;

- idéia central B. A atuação do Poder Judiciário não está interferindo no princípio da separação dos poderes do Estado. Está apenas resguardando um direito constitucional;

- idéia central C. Demonstrado o autor ser portador de uma doença e necessitar de um determinado medicamento, é curial seja o Estado obrigado a providenciar a sua implementação;

- idéia central D. O direito de todos os indivíduos à saúde deve ser garantido integralmente, a despeito de questões políticas, orçamentárias ou entraves burocráticos;

- idéia central E. A regra inscrita no artigo 196 da Constituição Federal é auto-apli- cável, não depende de regulamentação para ser exercida.

Na Figura 3 encontra-se a incidência das idéias centrais identificadas nos discursos dos juízes.

\section{COMENTÁRIOS}

Com base nos resultados encontrados, percebe-se que como órgão central do sistema jurídico, o Poder Judiciário não tem levado em consideração a política pública de medicamentos. Ele vem sustentando, principalmente, que questões políticas não podem disciplinar ou condicionar o exercício desse direito. Suas decisões têm com base unicamente a afirmação do direito à saúde e à assistência farmacêutica como direitos integrais e universais dos cidadãos brasileiros contida no arcabouço legal (Constituição Federal e Lei Orgânica de Saúde). O Poder Judiciário ignora que os direitos foram instituídos, de forma ampla e atrelada à elaboração de políticas sociais e econômicas.

As decisões jurídicas, como é normal no Estado de Direito, acabam por influir no âmbito da tomada de decisões coletivas da Secretaria de Saúde do Estado de São Paulo. Todavia, no tema em questão, pôde-se verificar que tais decisões definem políticas públicas a despeito das normas jurídicas estabelecidas para assegurar a eficácia e segurança dos medicamentos em território nacional. E como a totalidade das ações analisadas refere-se a indivíduos, pode-se concluir que em matéria de assistência farmacêutica, as decisões judiciais vêm influindo na função de tomada de decisões coletivas com base nas necessidades individuais dos autores. Tais ações ainda podem acobertar os interesses de determinados laboratórios farmacêuticos, responsáveis pela comercialização de inovações terapêuticas inacessíveis financeiramente aos autores.

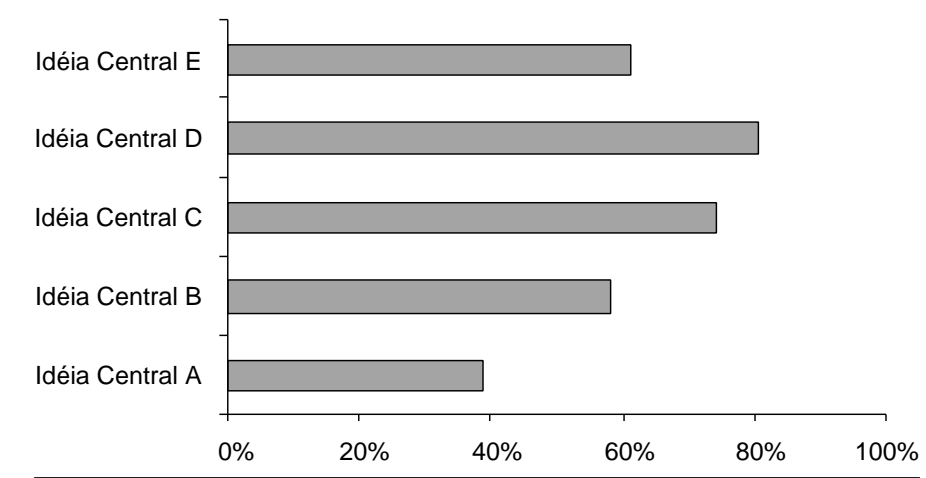

Figura 3 - Freqüência da incidência das idéias centrais dos juízes. Estado de São Paulo, 1997-2004. 
De acordo com Campilongo, ${ }^{3,4}$ a democracia constitucional pressupõe a separação entre os sistemas político e jurídico, cada qual perseguindo a sua função específica. Assim, a "judicialização da política" e a sobreposição das decisões judiciais e do arcabouço normativo às opções políticas representam uma ameaça à própria democracia e à complexidade interna desses sistemas. Amaral ${ }^{1}$ afirma que "o judiciário está aparelhado para decidir casos concretos, lides específicas que lhe são postas. Trata ele, portanto, da microjustiça do caso concreto" (p. 38). Quando a decisão jurídica não considera as políticas públicas, formalizadas juridicamente, que envolvem os direitos sociais, corre o risco de atuar fora dos limites estruturais do sistema jurídico. Disso resulta um Judiciário que decide politicamente - sem a estrutura necessária para atuar com essa lógica - e uma política judicializada, que acaba por incorporar o ritmo, a lógica e a prática das decisões judiciais. É o que a doutrina chama de "judicialização da política".,4 Os prejuízos da "judicialização da política" refletem-se na própria manutenção da democracia.

É claro que o Estado não pode ser negligente frente a indivíduos que correm risco de vida iminente. No entanto, como o direito à assistência farmacêutica depende de uma política pública para ser garantido, sob a perspectiva da justiça distributiva, é preciso que as necessidades individuais sejam contextualizadas dentro da política pública de medicamentos. Assim, a noção de justiça distributiva pode nortear a prestação coletiva e o próprio atendimento às necessidades terapêuticas individuais. Neste contexto, a preocupação de Dallari5 é relevante: "É preciso ter muito claro, entretanto, que para a real proteção judicial dos direitos humanos não é suficiente e, pelo contrário, é perigoso só cumprir as formalidades judiciárias, ter uma aparência de proteção judicial, que adormece a vigilância e que não é, porém, mais do que uma ilusão de justiça” (p.38).

A decisão jurídica do caso individual, portanto, posta a quem teve a oportunidade de acesso ao Judiciário, não pode desconsiderar a política pública desti- nada a garantir o mesmo direito de toda uma coletividade, sob pena de privilegiar os interesses de uma pequena parcela da população, conforme Santos. ${ }^{10,11}$ Lopes $^{8}$ indaga: "a prestação do serviço depende da real existência dos meios: não existindo escolas, hospitais e servidores capazes e em número suficiente, $o$ que fazer? Prestá-lo a quem tiver tido a oportunidade e a sorte de obter uma decisão judicial e abandonar a imensa maioria à fila de espera?" (p. 131).

O sistema jurídico deve garantir a existência de uma política pública de medicamentos pautada pela universalidade e eqüidade, que vise a assistência segura e eficaz à saúde dos cidadãos. Também, deve garantir a prestação ininterrupta de um serviço público de assistência farmacêutica para todos que dele necessitarem. Esta garantia refere-se às expectativas normativas, função que deve desempenhar o sistema jurídico. ${ }^{3,4, *}$ Nesse contexto, cabe à administração pública elaborar uma política e organizar um serviço que vise a atender, de forma integral e universal, o direito à assistência farmacêutica dos cidadãos. Para tanto, o sistema político precisa tomar decisões coletivas, com base nas principais necessidades de saúde da população e nos recursos disponíveis. Porém, acaba por adotar critérios de inclusão e exclusão de medicamentos dentre as ofertas do Sistema Único de Saúde, para que se possa atender os cidadãos de forma segura e equânime.

É de suma importância para a manutenção do equilíbrio social que o direito reconheça as políticas públicas, devidamente formalizadas perante o direito, como elemento integrante dos direitos sociais, conforme salienta Bucci. ${ }^{2}$ É mister que o sistema jurídico garanta que os indivíduos tenham acesso ao serviço público de assistência farmacêutica ofertado pelo Estado e padronizado pela respectiva política pública. Ou, no caso da inexistência do serviço ou da política, que garanta a assistência farmacêutica e determine a prestação do serviço. Para que este direito seja garantido de forma adequada para toda coletividade, é necessário que o sistema jurídico conheça os elementos da política pública de medicamentos.

\section{REFERÊNCIAS}

1. Amaral G. Direitos, escassez $\&$ escolha: em busca de critérios jurídicos para lidar com a escassez de recursos e as decisões trágicas. Rio de Janeiro: Renovar; 2001.

2. Bucci MPD. Direito administrativo e políticas públicas. São Paulo: Saraiva; 2002.
3. Campilongo CF. O direito na sociedade complexa. São Paulo: Max Limonard; 2000.

4. Campilongo CF. Política, sistema jurídico e decisão judicial. São Paulo: Max Limonard; 2002.

5. Dallari DA. 0 poder dos juízes. 2ª ed. São Paulo: Saraiva; 2002.

*Neves MCP. Entre Têmis e Leviatã: uma relação difícil [tese de doutorado]. São Paulo: Faculdade de Direito da Universidade de São Paulo; 1997. 
6. Kuntz R. Estado, mercado e direitos. In: Faria JE, Kuntz R. Qual o futuro dos direitos?: Estado, mercado e justiça na reestruturação capitalista. São Paulo: Max Limonard; 2002. p. 1-45.

7. Lefèvre $F$, Lefèvre $A M C$. $O$ discurso do sujeito coletivo: um novo enfoque em pesquisa qualitativa (desdobramentos). Caxias do Sul: EDUCS; 2003.

8. Lopes JRL. Direito subjetivo e direitos sociais: o dilema do judiciário no estado social de direito. In: Faria JE, organizador. Direitos humanos, direitos sociais e justiça. São Paulo: Malheiros; 2002. p. 113-43.
9. Minayo MCS. O desafio do conhecimento: pesquisa qualitativa em saúde. 8ae ed. São Paulo: Hucitec; 2004.

10. Santos BS. Introdução à sociologia da administração da justiça. In: Faria JE, organizador. Direito e justiça: a função social do Judiciário. São Paulo: Ática; 1989. p. 39-65.

11. Santos BS. Pela mão de Alice: o social e o político na pós-modernidade. 9a ed. São Paulo: Cortez; 2003. A sociologia dos tribunais e a democratização da justiça. p. 161-86.

12. Silva JA. Curso de direito constitucional positivo. 16a ed. São Paulo: Malheiros; 1999. 